Nathan C. Ellis, MD, Matthew T. McCarthy, DO and Dhimitri A. Nikolla*, DO

\title{
May-Thurner syndrome with left iliofemoral deep venous thrombosis
}

https://doi.org/10.1515/jom-2020-0324

Received December 23, 2020; accepted February 1, 2021; published online February 25, 2021

An 81 year old woman presented to the emergency department after experiencing left lower extremity swelling for four days prior. She had no associated chest pain or shortness of breath. She had a negative venous doppler ultrasound of the extremity one day earlier, but returned due to worsening pain and swelling. Physical examination revealed cyanosis and swelling extending from the left foot to the groin. Computed tomography (CT) venography revealed compression of the left common iliac vein (Images A and B, black arrowhead) between the right common iliac artery (Images A and B, white arrowhead) and the L5 vertebral body (Images A and B, black asterisk) and extensive iliofemoral deep venous thrombosis (DVT). The patient underwent mechanical thrombectomy and stenting of left common iliac vein, and she was prescribed long-term anticoagulation with apixaban. She was seen by her primary care provider five months postpresentation for her annual wellness examination and there were no residual issues. Besides the anatomic variant, no other provoking factors for DVT were identified.
May-Thurner syndrome (MTS) is an anatomic variant estimated to occur in up to $22-32 \%$ of the population [1-3]. It most commonly results from compression of the left common iliac vein between the right common iliac artery and a vertebral body [2]. MTS is a risk factor for left iliofemoral DVT which is associated with significant morbidity and mortality [4-6]. Ultrasonography has a sensitivity of $95 \%$ for proximal DVT, but has limited utility in the assessment of the inferior vena cava (IVC) and iliac veins; therefore, if iliofemoral DVT is suspected, CT or magnetic resonance venography may be considered [5]. Treatment of DVT associated with MTS is usually staged thrombolysis with or without IVC filter placement, then angioplasty with or without stenting of the left common iliac vein [7-9]. Only $5-7 \%$ of MTS-associated DVT cases receive anticoagulation alone $[1,10]$.

\section{Research funding: None reported.}

Author contributions: All authors provided substantial contributions to conception and design, acquisition of data, or analysis and interpretation of data; all authors drafted the article or revised it critically for important intellectual content; all authors gave final approval of the
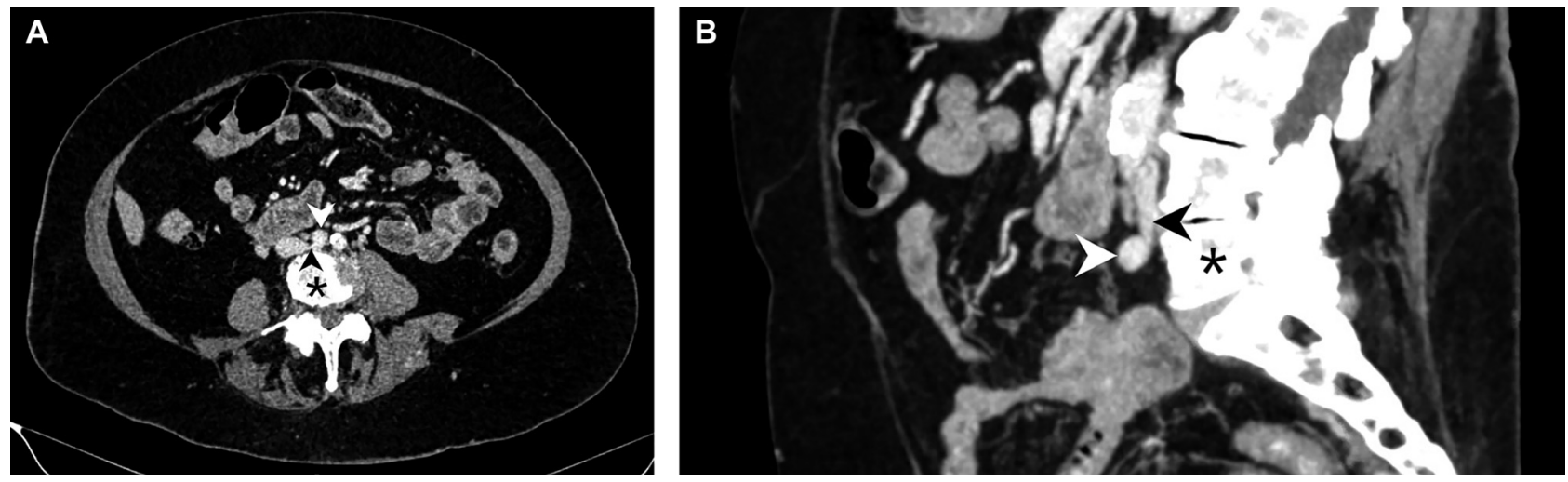

*Corresponding author: Dhimitri A. Nikolla, DO, Department of Emergency Medicine, Allegheny Health Network - Saint Vincent Hospital, 232 West 25th St, Erie, PA, 16544, USA, E-mail: dhimitri.nikolla@med.lecom.edu

Nathan C. Ellis, MD and Matthew T. McCarthy, DO, Department of Emergency Medicine, Allegheny Health Network - Saint Vincent Hospital, Erie, PA, USA 
version of the article to be published; and all authors agree to be accountable for all aspects of the work in ensuring that questions related to the accuracy or integrity of any part of the work are appropriately investigated and resolved.

Competing interests: None reported.

Informed consent: Informed consent was obtained from the patient described in this report.

\section{References}

1. Kaltenmeier CT, Erben Y, Indes J, Lee A, Dardik A, Sarac T, et al. Systematic review of May-Thurner syndrome with emphasis on gender differences. J Vasc Surg Venous Lymphatic Disord 2018;6: 399-407.e4.

2. Kibbe MR, Ujiki M, Goodwin AL, Eskandari M, Yao J, Matsumura J. Iliac vein compression in an asymptomatic patient population. I Vasc Surg 2004;39:937-43.

3. May R, Thurner J. The cause of the predominantly sinistral occurrence of thrombosis of the pelvic veins. Angiology 1957;8: 419-27.
4. Søgaard KK, Schmidt M, Pedersen L, Horváth-Puhó E, Sørensen HT. 30-year mortality after venous thromboembolism. Circulation 2014;130:829-36.

5. Liu D, Peterson E, Dooner J, Baerlocher M, Zypchen L, Gagnon J, et al. Diagnosis and management of iliofemoral deep vein thrombosis: clinical practice guideline. CMAJ (Can Med Assoc J) 2015;187:1288-96.

6. Salahuddin T, Armstrong EJ. Intervention for iliofemoral deep vein thrombosis and May-Thurner syndrome. Intervent Cardiol Clin 2020;9:243-54.

7. Bi Y, Yu Z, Chen H, Ren J, Han X. Long-term outcome and quality of life in patients with iliac vein compression syndrome after endovascular treatment. Phlebology 2019;34:536-42.

8. Mousa AY, AbuRahma AF. May-Thurner syndrome: update and review. Ann Vasc Surg 2013;27:984-95.

9. Rodrigues LDS, Bertanha M, El Dib R, Moura R. Association between deep vein thrombosis and stent patency in symptomatic iliac vein compression syndrome: systematic review and meta-analysis. J Vasc Surg Venous Lymphatic Disord 2021;9:275-84.

10. Hansrani V, Moughal S, Elmetwally A, Al-Khaffaf H. A review into the management of May-Thurner syndrome in adolescents. J Vasc Surg Venous Lymphatic Disord 2020;8: 1104-10. 